\title{
A travessia de um mito de origem amazônico: o Círio de Nazaré entre o moderno e o pós-moderno
}

\section{Our Lady of Nazaré: an amazonian myth of origin across modernity and postmodernity}

Larissa Latif - Pesquisadora do Centro de Estudos de Comunicação e Sociedade da Universidade do Minho, Portugal. Diretora de pesquisa da Associação de Investigação, Prevenção e Combate à Violência e Exclusão/IRENNE, Portugal. E-mail: larissalatif@gmail.com

\section{Resumo}

Neste artigo caracterizamos o Círio de Nossa Senhora de Nazaré como expressão de um mito de origem, o Mito da Senhora Teimosa, para, em seguida, levantarmos a questão de como um mito de origem dos tempos modernos submetido às pressões simultaneamente fragmentadoras e globalizantes da pós-modernidade mantém-se inteiro em suas bases. Em outras palavras, perguntamos se o mito permanece vivo e capaz de instaurar sentidos comunitários e identitários face à tendencia ao esvaziamento e à corrosão da narrativa mitológica quando exposta à comunicação de massas, na era da sua revolução tecnológica. Para responder a essas questões recorremos a um conjunto de teorias que ao longo do século $\mathrm{XX}$ trataram do mito, colocando-as em diálogo para, à sua luz, analisarmos o caso específico da narrativa do achado de Nossa Senhora de Nazaré e suas metamorfoses.

\begin{abstract}
This article characterizes Círio de Nossa Senhora de Nazaré as an expression of a myth of origin, namely the Myth of the Wilful Lady which thus raises the question of how a myth of origin from modern times, subject to post-modern pressures which are simultaneously fragmented and globalized can remain true to its fundamental aspects. In other words, the question we consider here is whether the myth remains alive, and if it is capable of generating feelings of community and identity, given the tendency of narrative mythology to corrode when exposed to mass communication in the era of the technological revolution. In responding to these questions, we revisit a variety of theories which addressed myths throughout the twentieth century, and based on these theories, we analyze the specific case of the narrative of Our Lady of Nazaré and its metamorphoses.
\end{abstract}

\section{Palavras-chave}

Amazônia. Mitos de origem. Identidades. Pósmodernidade. Imaginário. Círio de Nazaré

\section{Keywords}

Amazonia. Myths of origin. Identities. Postmodernism. Imaginary. Círio de Nazaré 


\section{INTRODUÇÃO}

A híbrida natureza dos processos identitários traz em si uma incontornável questão política. Com efeito, as políticas da identidade definem os espaços de poder no micro como no macrocosmo (FOUCAULT, 1979). Não é possível compreendermos os processos identitários nas culturas ocidentais contemporâneas sem indagarmo-nos acerca do lugar ocupado pelas identidades locais no mapa do poder simbólico, econômico e político, bem como das pressões e condicionantes das configurações de poder globais sobre as culturas locais (CANCLINI, 1997) no contexto desta que já foi chamada sociedade em rede (CASTELLS, 1999) ou "glocal" (SORIANO, 2006).

Diante disso, cabe-nos indagar se haverá de fato lugar para os mitos de origem locais ou nacionais nos dias de hoje, e que lugar será esse. Haverá nas nossas sociedades lugar para mitos de origem fundadores de identidades, "histórias verdadeiras", na concepção de Mircea Eliade (1989) ou, diferente disso, o lugar do mito é o da forma vazia, da deformação e da naturalização da história, conforme postula Roland Barthes (2009)?

Em busca de apreender o mito como parte ativa do processo cultural e não apenas como forma cristalizada de uma narrativa, recorremos a um conjunto de teorias para, num diálogo crítico com elas e a partir delas, construí-lo como objeto vivo. Uma tal abordagem se não nos dá o conforto de podermos delimitar um fenômeno perfeitamente controlável, dá-nos a possibilidade de compreendermos o processo pelo qual se atualiza a relação entre mito e sociedade na construção das identidades culturais contemporâneas.

Postulamos que para manter-se vigente no mundo contemporâneo, um mito de origem reinventa-se e, para isso, aceita e aproveita-se da incorporação de elementos novos. No limite, toda grande narrativa histórica de uma determinada sociedade é uma fonte inesgotável de alimento para o seu próprio mito de origem. Isto quer dizer que o mito não se esgota na narrativa do que se passou no illud tempore, não cessa de agregar novos sentidos e episódios a essa narrativa, trazendo o tempo heróico para os dias atuais, esbatendo-se as fronteiras entre o tempo mítico e o tempo histórico, criando-se uma dimensão temporal híbrida na qual se desenvolve o processo cultural.

Nenhum mito de origem ocidental que sobreviveu à revolução tecnológica das comunicações de massa sobreviveu intacto, carrega as marcas do esvaziamento e do rapto do sentido mítico original. Mas, em contrapartida, se o mito de origem sobrevive ainda, isto se deve em grande parte a uma capacidade de recobrir o processo de esvaziamento com uma nova camada de sentido que, se altera o mito

Novos Cadernos NAEA • v. 17 n. 2 • p. 23-52 • dez. 2014 
primeiro, ao mesmo tempo alimenta-o a partir de uma nova fonte de sentido que brota exatamente daquilo que tem o potencial de o esvaziar: a reprodutibilidade infinita, a capacidade de se repetir por todo lado e de significar qualquer coisa. Os processos identitários em tempos de globalização precisam mais do que nunca ser afirmados para dentro e para fora. Não podemos continuar a ser quem somos se o mundo não souber que somos, onde e quando somos.

Continuamos a existir graças à invenção do mundo pela capacidade fabuladora, mas o descentramento, a efemeridade, as ubiquidades virtuais do avanço tecnológico e da globalização passam a ser elementos ao mesmo tempo integrantes e desintegradores das nossas mitologias, forçam-nas a mudar. Por outro lado, elas, ao aceitarem a mudança permanecem e reforçam-se, mantém-se cheias de sentidos que são reconhecidos e valorizados pelas atuais populações. De resto, não podemos dizer que a tensão entre mudança e permanência tenham sido alguma vez algo de estranho ao imaginário e aos sistemas simbólicos da humanidade.

\section{A IMAGINAÇÃO SIMBÓLICA: ALGUMAS CONCEPÇÕES DESEN- VOLVIDAS AO LONGO DO SÉCULO XX}

Muito tem sido dito acerca da natureza do pensamento simbólico e mitológico desde o início do século XX em diferentes áreas do conhecimento tais como a psicanálise ${ }^{1}$ (FREUD, 1901, 1912; JUNG, 1976), a sociologia (DURKHEIM, 1912), a história das religiões (ELIADE, 1952, 1969), a antropologia (DUMÉZIL, 1924, 1939; LÉVI-STRAUSS, 1949,1955, 1962, 1970; GERTZ, 1973; TURNER, 1969) e as diversas vertentes da teoria do imaginário (BACHELARD, 1988, 1993, 1997; DURAND, 1998, 2002). Esses pensadores, dentre outros, reintegraram as atividades da imaginação humana ao corpo de objetos dignos de preocupação científica. Compreender o pensamento mítico passa a ser um caminho para compreender melhor o pensamento e a práxis humana.

Neste trabalho não nos detemos em todos os níveis do diálogo, muitas vezes polêmico, entre as diferentes tradições do pensamento sobre o simbólico e o imaginário. Apenas nos referiremos a um conjunto delimitado delas que nos permitem avançar rumo à reflexão que nos propomos a fazer acerca do Círio de Nazaré de Belém do Pará.

Indicamos neste parágrafo de abertura as datas das publicações originais das obras principais dos autores referidos, para dar uma melhor ideia de sua distribuição no tempo. No resto do texto, referimo-nos sempre à edição utilizada por nós e nas referências bibliográficas informamos as duas datas quando for o caso. 


\section{Do inconsciente coletivo às estruturas antropológicas do imaginário}

Sigmund Freud propõe a noção de inconsciente ainda no final do século XIX, na sua obra A Interpretação dos Sonhos (1901). Essa proposição terá grande repercussão ao longo de todo o século XX, mas não será unanimemente aceita. Se o inconsciente freudiano marcará, dentre outras, a obra de Claude Lévi-Strauss (1955) outras proposições de inconsciente são importantes para o desenvolvimento da teoria do imaginário, como é o caso da ideia junguiana do inconsciente formado por um inconsciente pessoal e por um inconsciente coletivo (JUNG, 2000).

Carl Gustav Jung identifica no inconsciente uma camada mais profunda que aquela na qual afloram as reminiscências pessoais (2000). Nessa camada, a que chamou inconsciente coletivo, repousam conteúdos transpessoais e universais. Para Jung e para os seguidores da teoria junguiana, nesse extrato mais profundo do inconsciente encontram-se os fundamentos estruturais da psiqué humana, comuns a toda a humanidade. Seu conteúdo é constituído primordialmente por arquétipos. Ao contrário do que muitas vezes tem sido repetido, Jung não admite a existência de imagens ou ideias inatas. Nise da Silveira esclarece que os arquétipos junguianos são "possibilidades herdadas para representar imagens similares, são formas instintivas de imaginar. São matrizes arcaicas onde configurações análogas ou semelhantes tomam forma” (SILVEIRA, 1992, p. 67). O arquétipo será, portanto, uma virtualidade que, quando atualizada, toma a forma de uma imagem arquetipal. Quanto aos mitos, são na tradição junguiana, fenômenos psíquicos que revelam a própria natureza da psiqué e resultam da incontornável propensão do inconsciente para projetar os fenômenos que decorrem no seu íntimo sobre o mundo exterior, traduzindo-as em imagens. "Os mitos condensam experiências vividas repetidamente durante milênios, experiências típicas pelas quais passaram (e ainda passam) os humanos. Por isso temas idênticos são encontrados nos lugares mais distantes e mais diversos" (op.cit., p. 118).

A teoria junguiana do arquétipo será retomada por Gilbert Durand (1988, 2000) na ampla discussão sobre o ressurgimento do mitológico e do simbólico na sociedade contemporânea que perpassará parte fundamental de toda a sua obra. Para Durand, o psiquismo profundo humano organiza-se em termos de dois grandes regimes antitéticos, o diurno e o noturno. No seio deste, entretanto, reside a capacidade de sintetização dos contrários, de reunião, capacidade esta inexistente no regime diurno, que se ergue sobre a separação, a classificação, o ordenamento.

O regime noturno permite não somente a convivência dos opostos mas a sua incessante fusão numa sucessão de imagens que o inconsciente coletivo

Novos Cadernos NAEA • v. 17 n. 2 • p. 23-52 • dez. 2014 
partilha e cujos sentidos transforma incessantemente, sendo esse o modo de funcionamento da atividade simbólica humana. No pensamento de Durand, o símbolo assume uma quádrupla função de equilíbrio: vital, psicossocial, antropológico e universal - teofania. Como restauradora do equilíbrio vital, a imaginação é resistência à finitude, à morte, uma idéia vinda de Bergson (função fabuladora) e partilhada por Eliade, entre outros. É, porém, resistência ativa, dinamismo criador cuja função eufemizante se diversifica em dois regimes antagônicos que se reencontram na narrativa, no mito, expressos na antítese do regime diurno e na antífrase do regime noturno.

$\mathrm{Na}$ esfera psicossocial, a imaginação é equilibradora dos dois regimes antagônicos, função que pode ser aplicada no campo da terapia psicológica, reintegrando o paciente pelo restabelecimento da função simbólica, mas que pode ser extrapolada para aquilo que Durand (2000) chamou pedagogia, a alternância do predomínio dos regimes de imagem numa dada sociedade. Essa sociatria, capaz de dosar com precisão esse equilíbrio de imagens, é a forma que assume a vida de uma cultura, uma sucessão de "realizações simbólicas".

$\mathrm{Na}$ esfera antropológica, o conjunto de todas as culturas seria o fator supremo de reequilíbrio de toda a espécie humana. A partilha e a aceitação das imagens vindas de outras civilizações seriam o meio de atingir um ecumenismo baseado na afetividade, realmente capaz de unir os homens. Essa é, em durand, a condição para o surgimento de uma antropologia do imaginário, na qual o espírito humano poderia se reconhecer no dinamismo polarizado dos regimes antagonistas (DURAND, 1988).

Ainda no pensamento durandeano, o símbolo se constitui numa revelação. A dialética dos regimes da imagem epifaniza a tradição universalmente partilhada dos símbolos, a vida do espírito que ultrapassa o biológico na negação da morte e se converte em teofania ao procurar uma imagem suprema para revestir a atividade espiritual. Imagem na qual a tensão dialética persiste, no desdobramento do deus em personificações antagônicas. O símbolo é a própria dialética em ação, é tensão criadora, instauradora de sentido e, por isso mesmo, "modelo da mediação do Eterno no temporal" (op.cit.).

\section{O mito como história modelo e a antropologia simbólica}

$\mathrm{Na}$ senda da história das religiões, Mircea Eliade (1989) define o mito como uma história modelo que relata acontecimentos no tempo mítico e que sacraliza o mundo, dotando-o de sentido e, portanto, de existência. Todo mito de origem ou de fundação passa pelo simbolismo do centro, pela escolha do lugar sagrado em torno do qual se realizam os ritos e se organiza a vida social. 
Eliade (1989) observa que os personagens do mito são os deuses ou os heróis ancestrais e que a história que eles protagonizam normatiza as relações dentro de uma sociedade, permitindo a ela existir ao atribuir-lhe um espaço, ao diferenciar o que e quem está dentro do que e quem está fora. Essa concepção do mito torna-o fundamental para a percepção dos processos identitários que são justamente processos de definição do "nós” em oposição aos "outros". Tanto os mitos de origem quanto os mitos iniciáticos exercem a função primordial de fundar as sociedades e as identidades no plano simbólico. Este, longe de ser um fantasma, uma irrealidade ou um engano, é antes pelo contrário o plano em que a vida se organiza e está fortemente ancorado não só nos momentos extracotidianos, como as festas, as comemorações, os rituais de toda ordem, mas também no dia-a-dia.

Para Lévi-Strauss, do mesmo modo, o simbolismo é anterior à sociedade, não uma consequência dela, é graças ao simbólico que a sociedade pode existir. De fato, a sociedade estrutura-se, em Lévi-Strauss, como linguagem, sendo o mito parte dessa linguagem, ou seja, parte do sistema de regras que organizam o mundo (LÉVI-STRAUSS, 1949, 1955,1962, 1970). No entanto, frente à oposição saussureana langue etparole, o mito ocupa uma posição suigeneris, podendo pertencer simultaneamente ao domínio da língua, sincrônico, domínio do tempo reversível, e ao domínio da palavra, diacrônico, domínio do tempo irreversível. Os elementos constitutivos da linguagem, língua e fala, estão, portanto, ambos presentes no mito que assim constitui-se como uma instância mais complexa que qualquer outra instância da linguagem. Os elementos constitutivos do mito, ao mesmo tempo que integram a linguagem, apresentam, como mitemas, propriedades específicas que não se reduzem aos morfemas, fonemas ou semantemas. Para resolver o problema do caráter ao mesmo tempo sincrônico e diacrônico do mito, Lévi-Strauss propõe um modelo em que as unidades constitutivas do mito não são relações de oposição isoladas, mas feixes de relações. Quando observadas do ponto de vista diacrônico, essas relações podem aparecer intervalares, mas, ao olhar sincrônico, elas revelam um novo sistema de referência temporal que satisfaz a hipótese inicial (LÉVI-STRAUSS, 1970, p. 231-232).

Suficientes e, muitas vezes, acertadas críticas já foram feitas às concepções estruturalistas da cultura, nomeadamente pelo esvaziamento da história e da tendência ao exagero da sincronia que pode levar a uma compreensão excessivamente rígida dos processos culturais, não lhes reconhecendo a capacidade transformadora. A redução de todo processo de criação de significado à estrutura redunda frequentemente na naturalização das hierarquias e inconstestabilidade das relações de poder. 
Não obstante, é inquestionável a contribuição de Claude Lévi-Strauss (1962) para a compreensão do pensamento mítico. Ao buscar compreender as formas de organização do parentesco em sociedades diferentes, Lévi-Strauss (1958) conclui que, embora dissemelhantes entre si e aparentemente arbitrárias, todas elas partem de um elemento comum, qual seja, a proibição do incesto. Do mesmo modo, ao voltar-se para a questão dos mitos, o antropólogo verifica que as histórias de caráter mitológico reaparecem um pouco por toda parte. Essa regularidade, para Lévi-Strauss, indica que não se tratam de simples criações fantasiosas ou absurdas da mente, mas histórias de cunho organizador das sociedades a que se referem (LÉVI-STRAUSS, 1962). Significar é a possibilidade de uma informação ser traduzida numa outra linguagem, o que implica regras de tradução. Sendo assim, explica o antropólogo, "falar de regras e falar de significado é falar da mesma coisa" (1987).

$\mathrm{Na}$ tradição da antropologia interpretativa norte-americana, a cultura é um sistema de símbolos, mas não um sistema puro que deve ser examinado de forma abstrata. Para Clifford Geertz, por exemplo, é preciso dar atenção ao comportamento, à ação social como via de acesso empírico aos sistemas de símbolos. Ao "inscrever" o discurso social, o etnógrafo não o "inscreve" em estado puro, mas apenas naquilo que os informantes podem levá-lo a compreender (GEERTZ, 1989).

Adotando um conceito semiótico de cultura, que segundo ele próprio adapta-se especialmente ao objetivo antropológico de alargamento do universo do discurso humano, Geertz vê a cultura não como uma instância causal, mas como um contexto, dentro do qual os sistemas simbólicos podem ser descritos com densidade, isto é, de maneira inteligível (op.cit.). Quer isto dizer que, para esta tradição, a cultura é comunicada por meio dos símbolos, sendo este um veículo para os significados e, portanto uma porta para a compreensão do sistema cultural, concebido como um texto. Podemos concordar com Ortner (2011) na afirmação de que o interesse da antropologia geertziana pelos símbolos está em perceber como estes operam como veículos de cultura (op.cit.)

Contrariamente, a antropologia simbólica britânica, na qual se destaca Victor Turner, confere maior importância à prática simbólica. Os símbolos não são vistos como meios para alcançar um sistema cultural que consistiria num ethos ou numa visão de mundo, mas como operadores práticos num sistema de relações sociais concretas (ORTNER, 2011). Na concepção processual da sociedade de Victor Turner (1969), o símbolo é a menor unidade de sentido da atividade ritual (TURNER, op.cit.). Para Turner, contrapondo-se a Lévi-Strauss, o rito é um lugar privilegiado para se observar os princípios estruturantes, mas 
também os processos de ruptura, crise, separação e reintegração, segundo a sua teoria do "drama social" (TURNER, op.cit). Se seguirmos o pensamento de Turner, veremos a sociedade como um processo sem fim em que estrutura e communitas se alternam continuamente e, nas sociedades complexas, podem acontecer de forma simultânea.

\section{As Sociologias do Imaginário}

Jean Duvignaud (1983) em sua sociologia do imaginário considera que as sociedades, para além das estratégias de regulação social que tenderiam ao reforço das estruturas, estabelecem mecanismos para viver o descontrole, a crise, a destruição, atividades subversivas que em nada postulam a sobrevivência das sociedades. Esses mecanismos, segundo o sociólogo francês seriam as festas, atos delirantes e niilistas que teriam como prolongamentos a criação barroca, a explosão capitalista e os fenômenos de transe e de possessão. Única provocação das sociedades à mudança e ao questionamento, a festa se apresenta em Duvignaud (op.cit.) como uma força que obriga a ultrapassar as limitações da cultura, à qual contesta e cujos contornos, portanto, altera (op.cit.). A festa pode surgir no momento da crise dos valores, quando ainda não se pressentem as normas do mundo novo que se prepara. A efervescência durkhiemiana ganha em Duvignaud uma conotação mais fortemente dionisíaca, que será retomada por Michel Maffesoli ao longo de toda a sua obra sobre o imaginário e a sensibilidade nas sociedades contemporâneas.

Com Michel Maffesoli, chegamos a uma perspectiva múltipla e plurifacetada sobre os imaginários coletivos (1985) e sobre os processos identitários (1993), entendidos como plurais e não exclusivos. A dimensão simbólica da vida constitui, para Maffesoli, o laço mais estreito entre os indivíduos numa dada sociedade (1998). Num contexto em que a mitologia impregna todas as formas da vida social os imaginários multiplicam-se e saturam o real, que por sua vez os corrobora em declinações simbólicas regionais e localizadas, donde a proliferação de heróis, ídolos e mártires que se convertem nas ligações entre membros incidentais de comunidades afetivas marcadas por uma intensa labilidade e imprevisibilidade emocional. É através da dinâmica do imaginário que os mitos ultrapassam a linearidade do tempo e reativam o fantástico e o dionisíaco, em contraposição à racionalidade e ao técnico-cientificismo moderno. Com Durkheim, aprendemos que a sociedade se adora a si mesma no ritual e com Maffesoli que as centralidades subterrâneas coexistem com a ordem vigente. Se há uma ética da estética em vigor e um vitalismo social explodindo nas práticas orgiásticas, ao lado dele, bem presente, está a ordem instituída, por vezes na união entre estado e igreja, por vezes na dissensão entre essas duas instâncias.

Novos Cadernos NAEA • v. 17 n. 2 • p. 23-52 • dez. 2014 


\section{A Semiosfera de Lotman}

A tradutibilidade e a delimitação do mundo do sentido são noções que reaparecem no pensamento de Yuri Lotman acerca da semiosfera, ou seja, da cultura pensada como um processo de produção e trocas de significados (LOTMAN, 1990). No entanto, a teoria semiótica da cultura procura superar o excesso de rigidez do modelo estruturalista, passando da ideia estática do sistema como conjunto de regras à ideia do sistema como processo, isto é, como movimento. Na semiosfera, a tradução é possível quando duas - ou mais linguagens - apresentam ao mesmo tempo elementos em comum, o que permite algum nível de compreensão mútua, e elementos díspares, o que permite a troca de informação nova entre os dois sistemas e, portanto a criatividade. Esta é tanto maior quanto mais afastada do centro do sistema, onde as regras tendem à rigidez e à autodescrição, ou seja, a partir do centro, o sistema enuncia suas normas de funcionamento que são menos observadas nos extremos da semiosfera que nas áreas mais próximas a ele.

São fundamentais para a teoria de Lotman sobre a semiosfera (op.cit.) as noções de centro e periferia como polos entre os quais os significados trafegam numa contínua atividade de tradução, mas também de produção de sentido permitida pela intensa e frouxamente regulada atividade nas zonas mais periféricas do sistema. Acerca do mito, Lotman (1990) afirma que não são narrativas, pois não apresentam enredo ou trama, não tem por objeto uma sequência de acontecimentos no tempo, mas a prescrição de comportamentos sempre iguais, num tempo cíclico, sempre igual a si mesmo, que envolvem um único herói. O mito também não apresenta caráter discreto, portanto não se desenvolve numa dimensão dialogal, sendo o caráter discreto o que permite a troca comunicacional entre os sujeitos. Assim, o mito não seria passível de inclusão de novos elementos e nem daria lugar ao inesperado (LOTMAN, 1990). Pela ausência de caráter discreto, o mito não poderia, segundo Lotman, assegurar a dimensão relacional que caracteriza uma semiosfera, ficando, assim, reduzido a uma instância formal.

\section{O mito como ideologia}

A concepção do mito em Roland Barthes põe em jogo ao mesmo tempo elementos estruturais e marxistas. Em sua crítica dos "mitos da vida cotidiana francesa" (2009, p. 11), mitos estes fabricados pelos mass media e típicos da ideologia burguesa, Barthes descreve o mito como um "sistema semiológico segundo" (2009, p. 205) no qual a preeminência da forma leva a um esvaziamento do sentido, embora não exatamente do mesmo modo que em Lotman. Barthes (2009) afirma que o sistema do mito só se pode constituir a partir de um sistema 
anterior, ao qual vai buscar o sentido. No entanto, ao ser capturado pelo mito, o sentido converte-se em forma, em significante vazio que somente significará o próprio mito. Barthes observa ainda que todo mito tem sua fonte na história, mas ao mesmo tempo, o mito deforma o conceito, naturaliza-o, transforma a história em natureza (op.cit, p. 221), e prossegue "o mito é um sistema de valores, mas o leitor comum o vê como um sistema de fatos" (op.cit, p. 223). O mito é, em Barthes, objeto de uma análise que procura demonstrar a naturalização do que é histórico e denunciar o abuso das falsas evidências. A espetacularização, para qual são fundamentais os meios de comunicação de massa, é denunciada como um processo através do qual a burguesia difunde as suas representações via imagens coletivas, dando maior aparência de universalidade para a sua cultura, a sua moral, a sua política, a sua arte, as suas mitologias.

\section{Mito, ritual e as identidades pós-modernas}

Muitos pensadores, partindo de diferentes pressupostos e com diversas filiações teóricas já se dedicaram a demonstrar a natureza fluida e descentrada das identidades na pós-modernidade. Pode-se argumentar em contrário com a desterritorialização crescente dos imaginários e com a multiplicidade identitária possível neste que Maffesoli chamou “o tempo das tribos” tempo de laços fluidos, alicerçados em afinidades estéticas e efêmeras (MAFESOLLI, 1988). Apagamse por essa fragmentação, descentramento e efemeridade as narrativas míticas a partir das quais fundamos o nosso mundo e o nosso lugar no mundo?

Segundo Anderson, a própria constituição das nações, essas "comunidades politicamente imaginadas como inerentemente limitadas e soberanas" (ANDERSON, 1993, p. 23) não pode prescindir da ideia de uma narrativa mítica. Esse mesmo autor sublinha que no século XVIII a ideia de nação - e os nacionalismos - vem substituir a religião no provimento de uma possibilidade de transformar a fatalidade em continuidade e da contingência em significado (ibid., p. 29). Muito embora a fragmentação, o descentramento e a efemeridade sejam incontornáveis nos processos identitários contemporâneos, as grandes narrativas heroícas não despareceram. Elas continuam a dizer-nos quem somos e a que territórios (tempos e espaços) pertencemos.

\section{O MITO DAS SENHORAS TEIMOSAS}

Denominamos Mito da Senhora Teimosa a um conjunto de narrativas de achados de imagens de Nossa Senhora, recorrentes na Europa e na América 
Latina. Num estudo finalizado em 2012 sobre um corpus de narrativas desse tipo inventariadas em Portugal e no Brasil, estabelecemos como variantes desse mito as narrativas que começam com o achado de uma imagem e terminam com a construção de um templo, seja ele uma igreja, uma capela, ou uma simples ermida (LATIF, 2012). É o caso do achado de Nossa Senhora de Nazaré em Belém do Pará, razão pela qual retomamos neste artigo essa denominação.

As narrativas de Senhoras Teimosas vinculam-se à sacralização ou ressacralização de um determinado local de culto, em torno do qual uma comunidade se organiza. Relevam, portanto do simbolismo do centro, pelo qual Mircea Eliade designa o ato de se demarcar um espaço ritual que coincide com o espaço miticamente delimitado in illo tempore pelos antepassados divinos ou heróicos. A relação entre o mito e o ritual no pensamento de Eliade permite a eterna repetição do tempo, o eterno retorno, o tempo cíclico da narrativa mítica transposto para a organização ritual da vida. A separação entre o sagrado e o profano demarca os limites da existência dentro de um espaço intimamente associado a um tempo não cronológico, um tempo que não foge como foge o tempo linear ou tempo histórico.

Nas histórias de Senhoras Teimosas o que está em jogo é uma dimensão prática que releva do preenchimento de condições materiais para a existência do culto, ou seja, a sacralização de um espaço e a instituição de pertencimento mútuo da Senhora a uma comunidade e da mesma comunidade à Senhora, o que tem conseqüências diretas no processo identitário local, pois a devoção à Senhora do lugar de origem atesta essa origem e investe o sujeito nos códigos sócio-culturais locais.

Essa dimensão prática se revela pela análise estrutural das narrativas que aponta sempre para o mesmo desfecho, a construção de um templo no sítio em que se deu o achado, sendo esta uma solicitação clara da Virgem que se dirige à comunidade por meio de um porta-voz ou expressa pelas fugas da imagem que, transferida para outro lugar, retorna sempre ao sítio do achado, até que ali seja construído um templo, que, normalmente, evoluirá de simples ermida à capela e, eventualmente, igreja, consoante o processo de institucionalização do culto.

As Senhoras Teimosas parecem mostrar que nem tudo o que acontece às comunidades lhes é perceptível, como se houvesse um fundo inconsciente ou primordial de onde emanam "ordens" desconhecidas que mais tarde podem vir a se revelar acertadíssimas, ou, nem tanto, mas, de qualquer forma, as comunidades aceitam o sem-razão da vida e do mundo, aceitam que haverá lógicas superiores não humanas quanto às quais nada se pode fazer. $\mathrm{O}$ mito atua, portanto como uma espécie de ode ao acaso, ao sem sentido, ao não compreensível aos humanos que, uma vez aceito, aplaca os deuses. 
Essa irracionalidade presente no mito das Senhoras Teimosas remete a uma dimensão dionisíaca, que, no entanto, convive no seio mesmo do mito com a resolução simbólica do conflito nas comunidades, o que nos leva a concluir que essa resolução não passa por fatores necessariamente racionalizantes, ou, melhor dizendo, por ações que se possam efetuar no campo do real. Este se submete à dinâmica simbólica que, por meio da sacralização do espaço e do tempo permite ultrapassar o momento conflitual pela instauração de uma nova ordem. Toda essa operação se processa numa instância inconsciente e instintiva, mágica, por assim dizer.

A função mediadora da Senhora, portanto, estabelece-se entre o inconsciente coletivo e a dimensão real na qual o conflito se instala, como meio divinizado de solução. A não percepção da hierofania como função equilibradora somente reforça a tendência dionisíaca das comunidades. O reequilíbrio vem das camadas mais profundas e desconhecidas da imaginação, não imersas na semiose até que a mediação simbólica conduza-as à luz da linguagem. É essa tradução que instaura a ordem nova onde a ordem anterior deixou de fazer sentido. Este não é um processo racionalmente compreensível, mas talvez seja a essa não compreensão que se deve a sua eficácia. A comunidade que resiste às razões divinas é que instaura a teimosia como função da narrativa mítica, sendo a teimosia da senhora a forma da redundância, da repetição que torna o seu desejo compreensível senão em suas razões, em sua vontade.

Em muitos casos, essa vontade é revelada a um só indivíduo, ele próprio assumindo uma função mediadora, como que delegada pela Senhora a quem a aceita e compreende. Arauto da teimosia, o "Achador" é via de regra alguém cuja posição social é a mais precária. Periféricos por excelência, fracos, sem poderes, os pastores, os velhos, as meninas mudas prestam-se a esse papel, pois, o inesperado, o irracional, o incontrolável, o dionisíaco, mais facilmente será proferido pela boca dos loucos e dos desajustados. Quando, num segundo ou terceiro momento a comunidade finalmente apropria-se da verdade revelada que o "Achador" anuncia, isto se dá pelo reforço que se constitui na base de elementos mítico-mágicos: as fugas misteriosas da Senhora ou, nalguns casos, estas fugas conjugadas a milagres ou prodígios. Com isso, podemos dizer que é em torno do dionisíaco que a ordem se reinstaura, sempre transformada, eternamente provisória e que, portanto, longe de estar ausente do processo semiológico que constitui uma cultura, o mito é parte fundamental desse mesmo processo.

As Narrativas de Senhoras Teimosas são narrativas míticas por excelência não por estarem isentas de linearidade, mas, exatamente por, ao contrário, serem capazes de estar simultaneamente dentro e fora do tempo, por reunirem 
circularidade e linearidade de modo a continuarem a ser o fundamento simbólico dos processos identitários e culturais nas suas respectivas comunidades. Para tanto, fez-se necessária uma abordagem complexa, por meio da qual o mito pôde ser compreendido em sua multidimensionalidade, no trânsito entre a narrativa em si e a relação processual da narrativa com a vida social, relação esta em que a sociedade e a narrativa constituem-se e reconstituem-se mutuamente, uma relação, portanto, de criação de significados culturais que passam a compor as sociedades e as narrativas.

Com Eliade vimos que os mitos de origem incidem sobre a sacralização do espaço pela hierofania (manifestação do sagrado), que, por sua vez, resulta da cratofania (revelação do poder). Ao tornar sagrado o espaço pela presença revelada do divino instaura o sentido da existência de uma sociedade. Numa aproximação com o pensamento de Lotman, podemos dizer que o mito estabelece a semiosfera ao diferenciar o que faz parte de uma cultura do que dela é estranho, do alo-semiótico, do que necessita de tradução para entrar em diálogo com o interior da semiosfera. O mito, ao determinar o centro, o lugar do templo, delimita ao mesmo tempo o espaço semiótico, o mundo é instaurado pelo sentido desde o centro até a sua última fronteira. Centralidade e periferia, portanto, são dimensões complementares no movimento do sistema, e sua existência resulta da mesma revelação.

A revelação, aqui, no entanto, não é concebida num sentido a-semiótico, antes pelo contrário, é a própria revelação do processo de criação que dá à existência o mito, para que ele possa dar à sociedade a existência. Mito e sociedade são, portanto, um complexo poético - no sentido de atuação da imaginação criadora - um movimento das forças do imaginário a atravessar o real e a instituir o simbólico, um movimento em que se conjugam as forças centrífugas e centrípetas, o princípio regulador que equilibra e o princípio dionisíaco, disruptivo, mas capaz de permitir a reinvenção para além da reacomodação de forças ancilosadas. É essa possibilidade criativa tornada possível na confluência entre a persistência e supressão da regra que faz emergir o mito como força identitária que se atualiza na cultura como semiosfera.

Os cultos do catolicismo popular realizam-se em torno dos conflitos de uma comunidade na qual grupos diferentes expressam suas vontades. Praticados à margem da liturgia oficial, eles expressam a potência comunitária e procuram a resolução desses conflitos sem que se recorra às autoridades instituídas, tais como a igreja ou o estado. O mito da Senhora Teimosa faz parte dessa linhagem dos cultos populares que se colocam, desde a origem, em posição conflituosa com os poderes instituídos, a saber o estado e a igreja. A porção dionisíaca 
dessas formas de devoção suscita invariavelmente uma reação negativa por parte desses poderes, à qual se seguem inevitavelmente estratégias de domesticação que passam pela aceitação total ou parcial dos cultos, desde que devidamente enquadrados nas normas oficiais.

A interferência das autoridades seculares no campo do sagrado (e aqui incluímos entre essas autoridades os padres, pois ao tratarmos do sagrado tratamos do simbólico e não do que segue a regra eclesiástica) leva a alterações na forma dos cultos populares que são em grande número de casos integradas tanto nos rituais quanto nas narrativas míticas.

No entanto, essas autoridades podem ser convocadas a atuar no contexto da narrativa mítica quando a comunidade não alcança por si mesma o reequilíbrio ou, ainda, podem interferir que fazendo parte do mesmo contexto cultural mais amplo. Entre eles se colocam duas maneiras de ver o ritual, uma ligada à ordem, à duração, ao controle, à estrutura. A outra, imersa na a-temporalidade, no orgiástico, no comunal.

Do ponto de vista da igreja e muitas vezes do estado, fica nítida a percepção dos cultos populares como algo que deve ser organizado, controlado, comandado por uma instância afastada da participação popular, uma entidade à qual um poder é delegado pela Igreja e que constitui uma elite em relação à comunidade em festa. Mas a crença popular é feita de separação, tanto quanto de comunhão, de desejo de apartar, tanto quanto de desejo de estar junto, de estrutura, tanto quanto de communitas. Essa contradição é que origina a narrativa mítica pela necessidade da refundação identitária de uma comunidade.

\section{NOSSA SENHORA DE NAZARÉ: UMA SENHORA TEIMOSA}

Analisaremos à luz do debate acima exposto o caso específico do Círio de Nazaré, em Belém do Pará compreendido como um complexo mitológico-ritual que nos remete aos sentidos coletivamente partilhados e aos processos pelos quais esses mesmos sentidos se transformam pela agregação ou emergência de novos significados, quer venham da esfera das narrativas, quer venham das práticas rituais, concebendo a ambas essas instâncias como único processo no qual o mito e o ritual integram um todo performativo. Quer isto dizer que para efeito da análise aqui empreendida não hierarquizaremos as narrativas mitológicas e os usos do corpo na festa em unidades de sentido diferenciadas, umas mais relevantes que as outras, por sua natureza performativa narrativa ou performativa ritual.

Novos Cadernos NAEA • v. 17 n. 2 • p. 23-52 • dez. 2014 
Nosso intuito é mostrar que no complexo mitológico-ritual do Círio de Nazaré, as narrativas históricas e as mitológicas fundem-se umas com as outras, passando a compor um único mito de origem que não cessa de se atualizar incorporando novos elementos de diversas naturezas e matrizes. Ao mesmo tempo esse mito está sujeito à apropriação por outros sistemas semiológicos e a uma drenagem de parte do seu sentido por esses sistemas. Postulamos uma compreensão complexa do processo estabelecido entre esses dois sistemas concomitantes que na contemporaneidade não mais podem ser separados. Isso implica uma concepção do mito na qual é preciso que sejam incluídas tanto as propriedades do mito de origem, fundador e recriador das identidades, quanto às características do mito quando apropriado pelo sistema semiológico segundo de que nos fala Barthes. De facto, nas sociedades contemporâneas, se são múltiplas e plurifacetadas as identidades, também os mitos não podem deixar de serem híbridos, complexos e por natureza contraditórios.

Consideraremos neste estudo três grandes narrativas que se agregam modificando-se umas às outras no processo mitológico-ritual do Círio de Nossa Senhora de Nazaré e uma dimensão fragmentadora e globalizante que sobre todas elas incide de modo cada vez mais intenso desde a segunda metade do século $\mathrm{XX}$ até os nossos dias. Essas três grandes narrativas, que, no fundo são uma só, serão vistas uma a uma aqui com o objetivo de demonstrarmos como uma narrativa mitológica incorpora episódios, acrescenta ação para além do primeiro desfecho, torna-se saga sem perder as suas propriedades de mito de origem. Após essa demonstração, procuraremos mostrar como a pressão fragmentadora e usurpadora do sentido pode ser revertida, tornando-se ela própria fonte de um novo sentido identitário não mais local, mas também global.

Escolhemos tratar três grandes narrativas que se agregam no complexo mitológico-ritual do Círio de Nazaré: a narrativa do achado, a narrativa da instituição da festa, a narrativa da introdução e da oficialização da corda dos promesseiros. A escolha das duas primeiras explica-se por serem as duas grandes narrativas inaugurais. A terceira por ser uma narrativa que ao longo dos séculos XIX, XX e XXI expõe de maneira exemplar os conflitos e a sua mediação, reforçando a tese do mito da Senhora Teimosa.

O culto a Nossa Senhora de Nazaré no Estado do Pará remonta ao período colonial. Os relatos históricos (D'AZEVEDO, 1901) indicam que a devoção foi ali instituída pelos Jesuítas, fixados no município da Vigia, ainda no século XVII. Entretanto somente no início do Século XVIII é que passou a ser realizado na capital, Belém. As origens desse culto estão imersas num universo em que convivem narrativas históricas e mitológicas, bem como diferentes formas de 
rituais de devoção. Na perspectiva adotada neste artigo, tanto essas narrativas de origem diversa quanto as diferentes práticas rituais compõem aquilo que chamamos complexo mitológico-ritual.

A lenda do achado de Nossa Senhora de Nazaré pode ser inserida na tradição das lendas de achado de santos, herança europeia trazida para a América Latina durante a colonização. Essa tradição, na Europa, relaciona-se por um lado com o recobrir dos cultos pagãos com a devoção mariana e, por outro, com o fortalecimento ou expansão da devoção pela sacralização de um espaço. As narrativas de santas achadas são narrativas míticas que culminam com a construção de um templo no lugar da aparição e sua análise aprofundada pode revelar o conflito entre os poderes instituídos e a força da comunidade. A partir da história de uma imagem achada, normalmente em lugares ermos, bosques ou topos de montanhas, a devoção é instaurada e a partir daí seguirá o curso da produção de sentido mitológico e ritual numa determinada comunidade.

No caso específico do achado de Nossa Senhora de Nazaré em Belém do Pará, ao relato mitológico, outras narrativas vindas de diferentes tradições míticas ou de fatos e acontecimentos registrados pela historiografia ou pelos jornais ou, ainda, simplesmente partilhados pela memória comum. Essas diferentes fontes narrativas acabam por vir a fazer parte de um todo mitológico que, ao contrário das teorias mais tradicionais sobre o mito, é dinâmico, mutável, processual. Não significa isto dizer que nada no mito permanece igual, do contrário não haveria narrativa possível, mas que essa permanência necessária associa-se à capacidade de mudança e, não raras vezes, cria com elas laços de dependência.

Procuraremos reconstituir o processo narrativo que vai do achado da imagem de Nossa Senhora e Nazaré às feições atuais da festa do Círio, pontuando as transformações pelas quais passaram tanto a narrativa quanto o ritual. $O$ objetivo será mostrar que, por um lado, a narrativa passa a agregar elementos externos e, por outro, estes incidem diretamente sobre as formas do ritual.

No início do século XX, o historiador Arthur Vianna $(1904)^{2}$ publicou uma versão do achado da santa, baseada nas narrativas orais que veiculavam os episódios milagrosos de aparecimento e desaparecimento desde o século XVIII e num manuscrito datado do fim do mesmo século, de autoria do Frei D. João Evangelista Pereira, então Bispo da Diocese de Belém, que teria colhido o relato da sua fonte primeira, o caboclo Plácido. O documento de Vianna é o primeiro a relatar a lenda do achado, embora outras referências mais antigas ao Círio de

2 Vianna, Arthur. Festas populares do Pará. Belém, Anais da biblioteca e arquivo público do Pará, tomo III, 1904.

Novos Cadernos NAEA • v. 17 n. 2 • p. 23-52 • dez. 2014 
Nazaré já possam ser encontradas ainda no século XIX e no início do século XX (BAENA, 1829; BAENA, 1833, D’AZEVEDO, 1901).

Segundo o relato de Vianna (op.cit., p. 237), por volta do ano de 1700, Plácido, descrito como filho de pai português e mãe indígena, caçador, habitante dos arredores de Belém teria encontrado às margens do igarapé do Utinga uma imagem de Nossa Senhora de Nazaré do Desterro, réplica daquela adorada em Portugal desde o século XII. Ao deparar-se com a pequena imagem entre as pedras do riacho do Utinga, Plácido leva-a para a sua casa e vai alertar a vizinhança de que se passava um milagre. A imagem, porém desaparece e, envergonhado diante dos outros, Plácido vai procurá-la na floresta, onde a reencontra no mesmo sítio onde aparecera incialmente. Plácido volta a conduzir a imagem para a sua casa e ela volta sempre para o lugar original, repetindo-se o mesmo por três vezes. Convencidos de que era o desejo de Nossa Senhora ali permanecer, Plácido e a sua comunidade não voltam a insistir, ficando a imagem a ser cultuada ali mesmo, na floresta, no seu nicho de pedras à beira d'água.

O governador da capitania, ao saber do acontecido, teria mandado buscar a imagem ao Palácio do Governo, de onde ela tornou a desaparecer para ser encontrada pela guarda palaciana no seu nicho entre as pedras com "algumas gotas de orvalho [que] rutilavam no seu manto como pérolas por entre carrapichos pardo-escuros que eram outras tantas provas mudas, mas eloquentes, da longa caminhada através da estrada" (VIANNA, 1904, p. 237). O governador teria então ordenando que se erguesse ali uma cabana, a primitiva ermida, hoje substituída pela Basílica de Nossa Senhora de Nazaré.

A estrutura narrativa que se inicia com o achado, prossegue com as fugas recorrentes e culmina com a construção do templo permite-nos incluí-la no Mito das Senhoras Teimosas como uma variante típica dessa tradição mitológica de origem europeia recriada na América Latina (LATIF, 2010). Mas a essa estrutura primeira outros episódios se vem associar, dando conta da instituição da festa e da procissão do Círio de Nossa Senhora de Nazaré, no final do século XVIII.

Passamos agora à narrativa da instituição da festa que como veremos, instaurase numa continuidade com a narrativa do achado ao encontrar uma justificativa miraculosa para uma determinação secular. Justificativa essa que é plenamente aceita pela comunidade, recoberta de sentido mitológico pela prática ritual.

Durante noventa e três anos permaneceu a imagem à beira do Utinga, onde se construiu uma ermida de palha, mais tarde substituída por outra de alvenaria. No ano de 1793, o então presidente da província do Grão Pará e Maranhão, D. Francisco Maurício de Sousa Coutinho, instituiu a festa de Nossa Senhora de Nazaré, cujo ápice era a romaria, na qual a imagem da santa era levada 
ao do Palácio do Governo e de lá novamente trazida, em cortejo, à sua ermida. Em torno desta, uma grande feira dos produtos da colônia se realizava de acordo com determinação do mesmo Sousa Coutinho.

Antônio Baena, ainda no século XIX, refere-se ao culto realizado no Utinga, assim como à instituição oficial do Círio, em 1793, pelo Capitão-Mor do Grão-Pará e do Rio Negro, Francisco Maurício de Sousa Coutinho:

[...] Determina [o Capitão-Mor] em três de Julho que se estabeleça uma Feira geral nos fins de Setembro de cada anno nos dias em que se costuma festejar Nossa Senhora de Nazaré, e no Largo da sua ermida; e que isto se faça publico por Editaes. Insinua á Confraria desta Ermida constituída que d' alli por diante deve solemnizar a festa do seu Orago com Novena, missa cantada e Procissão; e que a imagem da Senhora na véspera do primeiro dia da Novena será depositada na Capella do palácio do Governo a fim de ser transferida no dia seguinte de tarde em uma Berlinda para a sua Ermida, e nesse momento precedida por devotos de ambos os sexos concertados em alas, uma de mulheres em seges e duas de homens a cavallo, e que ele pessoalmente se adunaria a este religioso séqüito indo também a cavallo logo após do vehiculo da Imagem (BAENA; 1829, p. 227).

Também Artur Vianna, na obra já referida refere-se à primeira realização da festa e da procissão, acompanhadas por uma feira de produtos da colônia. De fato, Sousa Coutinho, respondendo a instâncias metropolitanas que clamavam pelos rendimentos da exploração colonial, ordenou que à feira geral a ser realizada durante a festividade fossem trazidos esses produtos:

Dos longínquos sertões do Estado, de toda a vasta bacia do Amazonas, correram índios de todas as raças, mestiços de todos os cruzamentos, a extasiar-se nas ruas da capital, para elles um belo centro de agradáveis attractivos; o largo cobriu-se de barracas de palha, onde o comerciante da cidade encontrou o excellente cacau, a perfumosa baunilha, o guaraná refrigerante, o magnífico arroz; o anil e o urucu manipulados no Estado, os bellos utensílios de cerâmica indígena, o forte tabaco, as primorosas rêdes de fio e de maqueira. O pirarucu salgado, o peixe boi (...) Realizouse assim em 1793, a primeira Feira de Nazaré (VIANNA, 1904, p. 130).

A fonte referida por Arthur Vianna para as informações acima é a cópia de uma circular do governador constante em livro da Intendência no hoje município de Faro. Infelizmente, nenhum documento aparece nos dias de hoje nos códices do Arquivo Público do Pará referente a qualquer aspecto da instituição do Círio de Nazaré. Por essa razão recorremos sempre aos historiadores locais, estes sim, como Vianna e Baena, em sua época, munidos de fontes primárias. Registrese aqui a inquietação quanto ao destino que terão tido tais documentos tão importantes para a história do Pará.

Novos Cadernos NAEA • v. 17 n. 2 • p. 23-52 • dez. 2014 
Baena (op.cit.) e, neste caso também Vianna (op.cit.), atém-se aos fatos históricos constantes das fontes primárias oficiais, mas a tradição popular acresce ao episódio da instituição da festa mais uma nota fantástica. Conta-se que, tendo ordenado a realização da festa e da feira, o Capitão-Mor cai doente. Angustiado por ver-se na iminência de não poder participar da comemoração, promete a Nossa Senhora fazê-la desfilar em carro da ermida ao Palácio do Governo e de volta ao ponto inicial. Seria essa a origem da procissão, pois, uma vez curado, Sousa Coutinho teria cumprido sua promessa, acrescentando-se um novo episódio milagroso que vem recobrir o fato histórico. Estaremos aqui diante de um exemplo da apropriação do mito por um sistema semiótico segundo, uma clara tentativa de mistificar um ato secular atribuindo-lhe um significado sagrado que não provêm da tradição do culto popular? É o mais provável. Entretanto, a tradição, ao aceitar e incorporar o episódio secular faz dele parte do mito e dá forma ao rito. Trazer e levar a imagem de Nossa Senhora constitui-se no núcleo ritual da procissão do Círio de Nazaré, assim como o Palácio do Governo e a ermida, hoje Basílica, constituem-se nos dois extremos do percurso até hoje vigente. Muito embora o Palácio do Governo tenha sido substituído pela Catedral Metropolitana, esses dois edifícios ocupam o centro do poder instituído na época colonial, são fisicamente vizinhos e representam a centralidade institucional em oposição à periferia, à floresta, lugar marginal e periférico escolhido por Nossa Senhora para se manifestar como é usual nas narrativas do mito da Senhora Teimosa.

O primeiro Círio realizou-se na tarde de 8 de setembro de 1793, tendo a imagem sido trasladada ao palácio do Governo, na véspera. O relato, mais uma vez, é de Arthur Vianna:

No dia seguinte, com todo o esplendor possível a uma estréia, desfilou do palácio a romaria; na frente e no couce marchava toda a tropa da cidade, os esquadros de cavalaria em primeiro lugar, os batalhões de infantaria depois e atrás as baterias da artilharia; adiante do carro da Santa seguiram uma fila de seges, palanques e serpentinas, com senhoras, e duas linhas de cavaleiros, trajando vestes de gala; a turba cercava o carro, e logo após este, destacava-se o governador e os membros das suas casas civil e militar, em primeiro uniforme e cavalgando bons cavalos (VIANNA, 1904, p. 237).

Ao longo do século XX, os relatos historiográficos se sucedem, muitas vezes referindo-se a Vianna ou Baena, outras coletando informações na imprensa de época ${ }^{3}$. O carro da santa era naquela época puxado por uma junta de bois.

A partir dos anos de 1980 aparecem os primeiros estudos de cunho antropológico, que se dedicam não apenas a descrição dos fatos, mas à interpretação da festa na tradição da antropologia estrutural cf. (ALVES, 1980, MAUÉS, 1995, 1999). Estes trabalhos são 
Dentro dele, o Bispo ou um padre levava ao colo a imagem de Nossa Senhora de Nazaré, costume que permaneceu até o ano de 1857, quando foi instituída a Berlinda de Nossa Senhora, escoltada, de início, pelos artífices marinheiros (CRUZ, 1952).

Aos poucos, durante o século XIX, novos carros foram sendo incorporados ao préstito ${ }^{4}$. O primeiro deles, o Carro de D. Fuas, também chamado Carro dos Milagres, foi incluído em 1805 pelo então presidente da Província, Noronha de Brito, o Conde dos Arcos, obedecendo a uma ordem de D. Maria I. Em 1826, O Barão de Itapecuru idealizou o Carro das Nações ou Carro dos Fogos, suprimido em meados da década de 1980, por causa do risco de acidentes durante a procissão, com o aumento do número de participantes na procissão (ROQUE, 1981).

Em 1855, a filha do $1^{\circ}$ vice-presidente, Ângelo Custódio, pagando uma promessa, desfilou vestida de Anjo Custódio, a cavalo. Outros cavaleiros também costumavam faze-lo no século XIX. Posteriormente, quatro carros dos Anjos passaram a figurar na procissão, junto com o carro de D. Fuas, servem para recolher os ex-votos no percurso (ROQUE, 1988).

No mesmo ano de 1855, passou a figurar o Carro dos Marujos, numa alusão ao milagroso salvamento de alguns marinheiros por Nossa Senhora de Nazaré, anos antes, em 1846. Os doze sobreviventes prometeram à Virgem desfilar com o escaler em que se haviam salvado às costas, no Círio. Proibidos pelas autoridades civis, militares e religiosas, deixaram-no pendurado no alpendre da ermida. Nove anos mais tarde, quando uma epidemia de cólera assolou a região, correu o comentário geral de que tratava-se de uma consequência da promessa quebrada. Foi então incluído na romaria um bote com 12 meninos dentro, representando os doze salvos do naufrágio. A partir desse episódio, criou-se a tradição de se dançar a marujada no Círio. O escaler foi substituído por uma miniatura do brigue S. João Batista que ia seguida pelos marujos (ROQUE, 1981).

Essa prática foi proibida em 1926 pelo Bispo D. Irineu Joffily, num esforço para romanizar o cortejo, transformando-o - numa procissão devota, com participação ordenada de associações religiosas, orações e cânticos pios (MAUÉS, 1995, p. 44). Sobre as questões envolvendo D. Irineu Joffily e as polêmicas em torno do Círio de Nazaré, foram registradas em diversas ocasiões. As retomaremos aqui, brevemente, a partir do trabalho publicado por Maués (1995).

fundamentais para a compreensão do Círio de Nazaré, mas não serão abordados aqui por estarem fora do escopo ao qual se propõe este artigo.

4 Rocque, Carlos. História do Círio e da Festa de Nazaré. Belém: Mitograph, 1988.

Novos Cadernos NAEA • v. 17 n. 2 • p. 23-52 • dez. 2014 
No inicio século XIX, a procissão mantinha a rígida organização do cortejo, mas teve acrescentados os carros de D. Fuas Roupinho, do Triunfo e do Anjo Custódio e o escaler do Brigue São João Batista. É também do século XIX que data a introdução da corda no Círio de Nazaré, oficializada em 1868. As carruagens foram suprimidas na segunda metade do mesmo século, e a procissão começou a ganhar as feições que apresenta hoje, com todo o percurso feito à pé. Quanto à festa, segundo os relatos escritos da época, ganhava mais atrações, como bandas de música, queima de foguetes e bailes.

Como uma espécie de desdobramento da Questão Religiosa, que repercutiu nacionalmente entre 1872 e 1875, foi deflagrada em Belém uma polêmica, em outubro de 1877. O Bispo D. Macedo Costa soube pela imprensa da realização de "representações indecorosas" no arraial da santa (MONTARROYOS, 1980). Decidiu, então, suprimir as funções religiosas da Festa de Nazaré. Os jornais, principalmente os que apoiavam o partido liberal, criticaram violentamente a atitude do Bispo (MAUÉS, 1995). Instigado pela irmandade de Nazaré, o povo forçou entrada na ermida, tocou os sinos, acendeu as velas e entoou uma ladainha, da qual participou grande número de fiéis.

D. Macedo Costa questionava a presença de alguns membros da maçonaria na irmandade de Nossa Senhora, o que acirrava a disputa, entre o clero e a irmandade, pela posse da igreja que substituiria a antiga ermida. Entre 1878 e 1879, realizaram-se vários "Círios civis", sem participação das autoridades religiosas e do clero, com o apoio total do governo da província. Somente com a mediação do Presidente da Província, José da Gama e Abreu, Barão do Marajó é que o conflito se resolveu.

Todos esses episódios fazem parte da narrativa do Círio de Nazaré dando conta das alterações sofridas ao longo do século XIX e do início do século XX. Embora as transformações tenham continuado a ocorrer ao longo da segunda metade do século XX e destas primeiras décadas do século XXI, neste trabalho não as acompanharemos até aos dias atuais, centrando-nos nos episódios que consideramos estruturadores da narrativa original, a saber: o achado da imagem, a instituição da festa, a incorporação da corda dos promesseiros. Essa escolha justifica-se pelo fato que são esses os três grandes pilares da fundação de sentido no Círio como mito de origem e ritual identitário. Outras transformações também fazem parte do processo, mas, pela sua profusão, não seria possível um exame mais aprofundado aqui. Por outro lado, parecem-nos, todas elas, tributarias destes três grandes episódios a cuja análise faremos agora.

O terceiro pilar da fundação de sentido identitário no Círio de Nazaré é a instituição da Corda dos Promesseiros. A história é conhecida pelos habitantes 
da cidade de Belém e a cada ano recontada nos cadernos especiais da imprensa local. Em meados do século XIX, o percurso da procissão já praticamente igual ao de nossos dias, passava, como ainda hoje, em frente ao porto do Ver-oPeso. Naquela altura, entretanto, o caminho era alagadiço e a Berlinda da Santa ficou uma vez atolada no lamaçal. As juntas de bois não a conseguiam libertar, optando as autoridades por atrelarem uma grossa corda diretamente ao carro e, substituindo a força dos animais pela força humana, mais numerosa, puxarem-na até que ela pudesse seguir caminho. A partir de então, criou-se o hábito de "pagar promessas na corda", com decisivas consequências para o futuro do Círio de Nazaré. A instituição da corda dos promesseiros alterou o desenho canônico da romaria que até então seguia as determinações de Roma para todas as procissões católicas em todo o mundo, com uma ordem pré-estabelecida segundo a qual vinham na frente as autoridades e os membros das classes altas, ficando as classes trabalhadoras relegadas ao fim do préstito. Os promesseiros da corda passam a ocupar um lugar na frente e, mais que isso, passam a estar fisicamente ligados ao carro que transporta a imagem da Senhora.

A corda dos promesseiros ou corda do Círio como é popularmente mais conhecida, passa por um processo de ressignificação que a leva a tornar-se, se um objeto de utilização prática, um utensílio, num dos mais poderosos fenômenos rituais e mitológicos dentro da festa e das suas narrativas. A narrativa da corda não se encerra no relato de como foi instituída e oficializada, ela continua sempre na diversidade de relatos dos milagres alcançados e das promessas pagas e reiteradas anualmente. Para o promesseiro da corda, o milagre pode ser a cura, a casa própria, livrar-se de uma dívida, ter um filho, ou, simplesmente, a graça de ser promesseiro. No ritual da corda, o corpo do devoto transforma-se em corpo ritual e a narrativa miraculosa passa a ser a narrativa dessa transformação.

Como é comum no caso de festividades originadas em torno de narrativas de Senhoras Teimosas, o Círio de Nazaré organiza-se em torno do conflito social, expressa as forças antagônicas e providencia um meio de equilibrá-las, não significando esse reequilíbrio neutralização ou supressão definitiva das contradições, bem como também não implicando uma restauração da mesma ordem, mas sempre a transformação da mesma.

A corda dos promesseiros foi sempre vista com desconfiança pela igreja e sofreu ao longo dos séculos inúmeras tentativas de supressão, nenhuma delas aceita pelos promesseiros. Esse conflito é parte da sua narrativa, a cada ano rememorada pelos participantes da festa e recontada com novos desdobramentos pelos veículos de comunicação de massa, jornais, rádios, televisões, portais da internet. A narrativa da corda pode ser resumida na imagem do seu corte quando feito à revelia dos promesseiros.

Novos Cadernos NAEA • v. 17 n. 2 • p. 23-52 • dez. 2014 
Para o promesseiro da corda é essencial chegar com ela até ao final da procissão, objetivo que é dificultado ou impedido quando, afirmando razões de tempo ou de segurança, a organização da festa manda que a corda seja cortada em pedaços e separada da berlinda ainda durante a procissão. Quando isso acontece, os promesseiros costumam continuar o trajeto ainda presos uns aos outros pelos pedaços da corda, mas, principalmente, unidos pelo sentido do corpo ritual. A corda deve levar Nossa Senhora da Sé à Basílica, como na primeira vez em que foi atada à berlinda. O promesseiro compreende o corte prematuro como um "sequestro de sentido". Recobre, então, a corda cortada de um significado novo: se já não é a força que levará Nossa Senhora de volta à sua casa, é algo que a ela foi tirado, a força do seu povo, que a ela deve ser restituída. Prosseguir até o final do percurso torna-se o objetivo do promesseiro e a ação que o move é a de restituir o símbolo ao seu lugar devido. O símbolo aqui é o próprio corpo do promesseiro, transfigurado e ressignificado no contexto ritual. A história da persistência de cada um deles e de todos juntos é o núcleo de uma narrativa de resistência que se agrega à teimosia da Senhora, fazendo de seus filhos também teimosos e resistentes.

As questões do tempo e do risco físico são de importância capital para a compreensão dos ritos sagrados. O tempo ritual, como o tempo mitológico não se pode medir pelos relógios e o risco físico faz parte de todos os ritos de passagem e de iniciação. Ao questionar a duração e o perigo, a organização da festa instaura uma cisão no tempo e no espaço sagrados que somente é restabelecida pela insistência dos promesseiros. $\mathrm{O}$ conflito que aqui se estabelece é vital para o drama ritual revivido a cada ano na festa do Círio de Nazaré, a festa de uma Senhora Teimosa.

\section{CONSIDERAÇÕES FINAIS: O RAPTO DA SENHORA TEIMOSA, MITO DE ORIGEM OU MITO MEDIÁTICO?}

Vimos nas páginas acima como o mito de Nossa Senhora de Nazaré, em Belém do Pará, reveste-se das características de um mito de origem ibérico recriado na América do Sul, ao qual chamamos o Mito das Senhoras Teimosas. Pudemos analisar a estrutura da narrativa e perceber o jogo de mudanças e permanências que põe em relação direta o sincrônico e o diacrônico, as emergências do histórico no mitológico e reciprocamente. Com isso, pudemos perceber um pouco mais sobre o processo identitário que se desencadeia em torno do mito de origem da Senhora Teimosa em sua manifestação encontrada em Belém do Pará, Nossa Senhora de Nazaré. 
Propusemo-nos no início deste trabalho a procurar perceber o quanto de mito de origem persiste no que tange a uma narrativa que faz parte do imaginário contemporâneo, no contexto do processo cultural em que vivemos, no qual as identidades locais não se podem constituir sem que esteja presente a dimensão global na qual elas têm que encontrar um lugar simultaneamente dentro e fora da globalidade, um lugar que lhes permita a um tempo serem identidades diferenciadas e participarem do mundo global.

Ao longo dos séculos os relatos de teor claramente mitológico e os de teor historiográfico agregam-se na narrativa do Círio de Nazaré, passando os últimos a fazer parte da instância do sagrado. Parte das interferências seculares são ressignificadas quando a comunidade incorpora ao mito e ao ritual os elementos exteriores. Não obstante a eficácia desse processo, não podemos deixar de considerar que Nossa Senhora de Nazaré é uma variante de um mito moderno, uma narrativa que opõe o sagrado e o profano nos moldes da mediação pelo sagrado de um conflito entre a comunidade e o Estado ou a igreja instituída, característico da modernidade. Cabe, portanto, procurar compreender em quem medida a eficácia se mantém no contexto da contemporaneidade e seus fenômenos simultaneamente fragmentadores e globalizantes. Não é possível refletirmos sobre os processos culturais contemporâneos sem atentarmos para a imensa pressão da comunicação de massa e do seu sempre crescente aparato tecnológico que pulveriza o espaço e o tempo nos ambientes virtuais, fragmenta o mito numa miríade de imagens dele próprio, comprime o contexto, desenraiza e globaliza a narrativa e a ação ritual.

Mas não só no território sacralizado está presente o Círio de Nazaré. A transmissão ao vivo ocupa as televisões locais desde a década de 1960. As imagens na televisão perdem a dimensão mais viva da festa, que não é feita para ver, mas par viver. O Círio de Nazaré é rico em imagens, mas elas não são fáceis de apanhar por câmaras paradas e planos abertos. Para além disso, é uma festa de cheiros e temperaturas, na qual são convocados todos os sentidos do corpo. A transmissão televisiva a reduz a uma única dimensão asséptica e monocromática, criando um vazio de significado, uma desintegração dos sentidos mitológicos e rituais, uma espécie de sequestro da festa para um universo frio no qual ela não pode sobreviver.

Ver o Círio pela televisão em Belém, no entanto, tem uma conotação particular. Ficar em casa não significa estar longe da festa e, da transmissão monótona - pois é impossível apanhar sem uma complicada edição de imagens a vida da procissão- o que interessa é saber em que ponto do percurso a Senhora vai. O habitante de Belém conhece a procissão como a palma das suas mãos, a

Novos Cadernos NAEA • v. 17 n. 2 • p. 23-52 • dez. 2014 
informação da televisão tem o efeito de um dispositivo de memória que o remete ao palmilhar das ruas, ao calor, aos cheiros, aos sentidos todos da festa.

O mesmo será válido para os habitantes de Belém que foram viver em outras cidades ou países e acompanham a procissão pela internet? Em parte. A memória é ativada, certamente, mas não é reforçada pelos sons que vêm da rua, pelos ritmos alterados da cidade, pelo cheiro da comida do Círio que atravessa todas as janelas. Ainda assim, tudo isso pode ser revivido na memória do corpo, embora enfraquecido pela imagem vazia de acontecimentos, mar sempre imóvel de gente que passa, nas câmeras fixas ao longo de horas, como se estivesse sempre ali a mesma multidão, a repetir-se indefinidamente.

Ainda mais abstratas serão essas imagens para aquele que nunca esteve de corpo presente na festa. Para este, nada significam as paradas assinaladas no percurso, a identificação dos nomes das ruas, as curvas, os corredores mais estreitos, os pontos de maior dificuldade ou as celebrações patrocinadas pelas empresas, associações profissionais, condomínios residenciais ao longo da procissão. O belenense sabe que cada uma dessas paradas significa um trecho percorrido e assinala o tempo do ritual. É possível calcular aproximadamente o quanto falta para o final da procissão e o início do almoço do Círio. Para o devoto que está fora, os comentários e postagens nas redes sociais convertem-se em uma nova forma de participar da festa, uma forma de esbater a distância geográfica, diluí-la na proximidade ritual. A virtualidade do meio digital esvazia o rito e drena o sentido mitológico, mas, para aquele que pertence à comunidade, o significado é reinvestido pela memória. Como em todo processo de reinvestimento de significado, há elementos que se perdem e outros que passam a integrar o sentido original, contribuindo para a dinâmica de transformação do mito. Participar à distância introduz a dimensão global do ritual, o estar perto mesmo quando se está longe. O apagamento virtual da distância inaugura uma nova forma de celebrar a identidade, uma forma de viver o local na deslocalização, de reencontrar o local no global.

Todas essas dimensões escapam ao estrangeiro, àquele que desconhece o espaço físico transformado no tempo festivo, àquele que "não nos pertence". Mas é essa virtualidade parcializante transmitida ao "mundo lá fora" que assume um papel incontornável na contemporaneidade, o de tornar o fenômeno local globalmente conhecido, globalmente reconhecido, muito embora esse conhecimento seja sempre reduzido e redutor, alimenta um imaginário, este, incontrolável, como todo imaginário, sobre a festa, sobre a cidade de Belém, sobre os habitantes, sobre os modos de viver a festa. Abre-se assim, uma miríade de possibilidades narrativas que existirá, multiplicar-se-á ou desaparecerá 
independente de nós e dos nossos modos de investir os sentidos do "nosso" mito. Para nós, ela se reveste do incontornável poder de tornar mundial, pelo menos no imaginário, aquilo que é local.

Ainda uma última dimensão dos processos de fragmentação do sentido será examinada aqui. Ela diz respeito aos usos do Círio e suas imagens para fins publicitários. Já vimos que as interferências externas sobre o complexo mitológicoritual do Círio de Nazaré fizeram-se sentir desde o início. Na verdade, a mediação entre o desejo do sagrado da comunidade e o desejo secular é que é o objeto último da narrativa mítica. A teimosia da senhora é que se impõe à determinação do governador na fixação do local do culto. No momento da instituição da festa a determinação de Estado por razões econômicas é recoberta de sentido mítico, transformando-se a forma original do culto, bem como acrescentando a narrativa mítica um episódio novo. Note-se que a associação do primeiro Círio de Nazaré à realização de uma feira inscreve no mito mesmo, assim como na origem do ritual tal como se consagrou, a relação com o comércio.

Essa relação intensifica-se ao longo do século XX e destes inícios do século XXI ao mesmo tempo em que o Círio de Nazaré torna-se cada vez mais um fenômeno de massas e um fenômeno midiático. Desde os primeiros anos da procissão os jornais locais dedicaram espaço à cobertura da festa e esta tendência foi acompanhada pela televisão, a partir de 1961 e, mais recentemente pela internet. Ao lado da mediatizaçao crescente, a utilização da festa e de seus símbolos em peças publicitárias nos diversos meios também se tornou uma constante. No Círio vende-se de tudo e o Círio vende tudo. Quartos em hotéis, pratos em restaurantes, eletrodomésticos, shows, vassouras, brinquedos, fogos de artifício, computadores, viagens de avião. Mas para que tudo isso se venda, é preciso antes que o Círio venda-se a si mesmo. A maior festa católica do mundo, o Natal dos paraenses, a festa da Rainha da Amazônia são slogans que primeiro afirmam o sentido do ritual para, em seguida, chamar ao consumo como mais uma das tantas maneiras de se participar da festa e de reforçar o sentido identitário, para os que são da terra, e mostrar essa mesma identidade aos que vêm de fora, consumidores do fenômeno identitário antes de tudo, que deixam o seu pagamento nos hotéis, restaurantes, agências de turismo, lojas de souvenirs.

A publicidade invade o Círio de Nazaré de dentro para fora. Não apenas na televisão, no rádio, nos cartazes espalhados pela cidade, mas também nas "homenagens" realizadas ao longo da procissão pelos bancos e empresas sediados nas avenidas que fazem parte do percurso. Essas eclosões em pleno ritual do poder secular do dinheiro têm a função de inscrever esses agentes no seio do processo simbólico. Drenam, por isso, o sentido ritual, reduzem a própria

Novos Cadernos NAEA • v. 17 n. 2 • p. 23-52 • dez. 2014 
romaria à marca, ao slogan, ao produto ou ao serviço, procuram condensar os significados mitológicos-rituais da festa no pequeno espaço em frente à porta da empresa e no recorte de tempo que a "homenagem" dura. Esse recortar do tempo e do espaço rituais criam um vórtice por onde o sagrado escoa.

Essas pequenas narrativas, ou fragmentos de narrativas não terminam com a construção de um templo ou o agradecimento por uma graça alcançada. Elas terminam com um consumidor feliz ou frustrado, consoante a possiblidade de adquirir ou não o bem. Mas isso apenas quando vistas isoladamente. Tomadas em seu conjunto, numerosas e exaustivamente repetidas, elas são reabsorvidas pelo mito que tinham absorvido. Se, podemos considerar que esses fragmentos drenam o sentido do mito de origem, reduzem-no, alimentam-se dele e o tornam mera forma vazia que só significa uma marca de eletrodoméstico, um banco ou uma empresa de mineração, não é menos verdade que, por serem tantas e tão semelhantes entre si, acabam por desvanecerem-se na imagem primordial e voltam a fazer parte do mito de origem, reforçam-no, multiplicam-no, tornam-no infinito, incontável, imenso. O uso excessivo da imagem pode matar o sentido, mas, no caso do Círio de Nazaré, o sentido que morre é o sentido de segunda mão.

Isso acontece pelo fato de que a imagem roubada é roubada muitas vezes e veiculada ao mesmo tempo por diferentes ladrões de sentido. O banco, a loja de roupas, o restaurante, a companhia aérea, todos roubam o mesmo. E exibem ao mesmo tempo a mesma forma esvaziada como se fosse um sentido primeiro. Mas como ver sentido primeiro na marca de um produto se todos os produtos do mundo se vendem com a mesma imagem? O excesso da imagem apaga o fragmento, reconduz o significante ao seu sentido, realimenta o mito de origem.

Como pode uma narrativa mitológica não apenas sobreviver, mas, ao mesmo tempo, tornar-se cada vez mais conhecida, maior, mais abrangente, mais global, por assim dizer, sem que se perca aquilo de que ela se alimenta, os sentidos identitários locais que, reinventados, permitem que ela continue a reinstaurá-los? O preço é a transformação. Transformar-se, para o mito da Senhora Teimosa não é apenas alterar a história narrada, mas a forma mesma de narrar. Incluir episódios ou excluí-los e manter a estrutura da grande narrativa é mudança na superfície. A grande alteração é ser contada não mais como uma história que vai de uma origem para um desfecho, seja oralmente ou corporalmente ou ambos ao mesmo tempo. A grande alteração é ser contada como um cartaz que funde numa única imagem a Senhora achada, a floresta, a multidão da festa e um aparelho de telefone celular em 12 prestações no seu cartão de crediário. Ou ser reconhecida pela sua imensidão não mais no número de romeiros na rua, mas no número de acessos online ou, ainda, pela capacidade se ser reconhecida em qualquer lugar 
do mundo. Mais que a transformação, o aceitar pulverizar-se numa diversidade de narrativas possíveis, umas mais breves, outras menos, umas que deixam rastro, outras que simplesmente esgotam-se ao eclodirem, todas tributárias da mesma narrativa mãe, mas todas abertas, potencialmente infinitas, incontroláveis.

\section{REFERÊNCIAS BIBLIOGRÁFICAS}

ALVES, I. M. da S. O Carnaval Devoto. Um estudo sobre a Festa de Nazaré, em Belém. Petrópolis: Vozes, 1980.

BACHELARD, G. A água e os sonhos. São Paulo: Martins Fontes, 1997.

BACHELARD, G. A Poética do devaneio. São Paulo: Martins Fontes, 1988.

BACHELARD, G. A Poética do Espaço. São Paulo: Martins Fontes, 1993.

BAENA, A. Ensaio Corográfico sobre a Província do Pará. Belém: Tipografia de Santos e Menor, 1833.

BAENA, A. L. M. (1869). Compêndio das eras da Província do Pará. Belém: UFPA, 1969 (Coleção Amazônica, série José Veríssimo).

BAENA, A. L. M. Ensaio Corográfico sobre a Província do Pará. Belém: Tipografia Santos e Menor, 1839.

BARTHES, R. Mitologias. Rio de Janeiro, Difel, 2009.

CANCLINI, N. G. Culturas Híbridas. Estratégias para entrar e sair da modernidade. São Paulo: Edusp, 1997.

CASTEllS, M. A sociedade em Rede. São Paulo: Paz e Terra, 1999.

CRUZ, E. Procissão dos Séculos. Belém: [s.n.], 1952.

D’AZEVEDO, J. L. (1901). Os Jesuítas no Grão-Pará. Suas missões e a Colonização. Belém: Secult, 1999.

DUMÉZIL, G. (1968). Mythe et Épopée. Paris: Quarto Gallimard, 1995.

DUMÉZIL, G. Mythes et dieux des Germains - Essai d'interprétation comparative. Paris: Puf, 1939.

DURKHEIM, É. (1912). As formas elementares da vida religiosa. São Paulo: Martins Fontes, 2000.

DUVIGnAUD, J. Festas e Civilizações. Tradução de L. F. Raposo Fontenelle. Fortaleza: UFCE, 1983.

DUVIGNAUD, J. L'oubli ou la chute des corps. Arles: Actes Sud, 1995. 203 p. 
DUVIGNAUD, J. Le don du rien: essai d' anthropologie de la fête. Paris: Stock, 1977.

DUVIGNAUD, J. Sociologia del Teatro: ensayo sobre las sombras colectivas. Mexico: Fondo de Cultura Económica, 1966.

ELIADE, M. Aspectos do Mito. Lisboa: Edições 70, 1989.

ELIADE, M. Images et Symboles. Paris: Gallimard, 1980. 238 p.

ELIADE, M. O Mito do eterno retorno. Tradução de Manoela Torres. Lisboa: Edições 70, 2000.

ELIADE, M. O Sagrado e o Profano. A Essência das Religiões. Tradução de Rogério Fernandes. Lisboa: Edição Livros do Brasil, 235 p.

EliADE, M.; COUliAnO, I. P. Dicionário das Religiões. Tradução de Ivone Castilho Benedeti. São Paulo: Martins Fontes, 1999. 342 p.

FINKIELKRAULT, A.; SORIANO, P. Internet. El éxtasis inquietante. Buenos Aires: Livros del Zorzal, 2006.

FOUCAULT, M. Microfísica do poder. Organização e tradução de Roberto Machado. Rio de Janeiro: Graal, 1979.

FREUD, S (1900-1901). Interpretação dos Sonhos. v. 4/5. Rio de Janeiro: Imago, 1991.

FREUD, S. (1912). Totem e Tabu. v. 13. In: FREUD, S. Edição standard brasileira das obras Psicológicas completas de Sigmund Freud. Rio de Janeiro: Imago, 2006. GEERTZ, C. (1973). A Interpretação das Culturas. Rio de Janeiro: LTC, 1989.

JUNG, C. G. (1976). Os Arquétipos e o Inconsciente Coletivo. Petrópolis: Vozes, 2000.

JUNG, C. G. O Homem e seus símbolos. São Paulo,:Cultrix, 1987.

LÉVI-STRAUSS, C. La Pensée Sauvage. Paris: Plon, 1962.

LÉVI-STRAUSS. Ensaios de Antropologia Estrutural. Rio de Janeiro: Tempo Brasileiro, 1970.

MAFFESOLI, M. Au creux des apparences: Pour une éthique de l'esthètique. Paris: Plon, 1990.

MAFFESOLI, M. L'Ombre de Dyonisos. Contribution a une Sociologie de L'Orgie. Paris: Librairie de Méridiens, 1985.

MAFFESOLI, M. La Contemplation du Monde. Paris: Le Livre de Poche, 1993.

MAFFESOLI, M. O Conhecimento Comum. Rio de Janeiro: Brasiliense, 1998.

MAUÉS, R. H. Padres, pajés, santos e festas: catolicismo popular e controle eclesiástico. Belém: Cejup, 1995. 
MAUÉS, R. H. Uma outra invenção da Amazônia: religiões, histórias, identidades. Belém: Cejup, 1999.

MONTARROYOS, H. Festas profanas, alegrias ruidosas. A imprensa no Círio de Nazaré. Belém: [s.n.], 1980.

ROCQUE, C. História do Círio e da Festa de Nazaré. Belém: Mitograph, 1981.

TURNER, V. W. (1969). Le phénomène ritual: structure et contre-structure. Paris: PUF, 1990.

VIANNA, A. Festas populares do Pará. Anais da Biblioteca e Arquivo Público do Pará, Belém, t. III, 1904. 